\title{
Soil Phosphorus Uptake by Continuously Cropped Lupinus albus A New Microcosm Design
}

\author{
Journal Article \\ Author(s): \\ Bayon, R. C. le; Weisskopf, L.; Martinoia, E.; Jansa, J.; Frossard, E.; Keller, F.; Föllmi, K. B.; Gobat, J.-M. \\ Publication date: \\ 2006-05 \\ Permanent link: \\ https://doi.org/10.3929/ethz-b-000001956
}

Rights / license:

In Copyright - Non-Commercial Use Permitted

Originally published in:

Plant and Soil 283(1-2), https://doi.org/10.1007/s11104-006-0021-4 


\title{
Soil phosphorus uptake by continuously cropped Lupinus albus: A new microcosm design
}

\author{
R.C. Le Bayon ${ }^{1,5}$, L. Weisskopf ${ }^{2}$, E. Martinoia ${ }^{2}$, J. Jansa ${ }^{3}$, E. Frossard ${ }^{3}$, F. Keller ${ }^{2}$, \\ K.B. Föllmi ${ }^{4}$ \& J.-M. Gobat ${ }^{1}$ \\ ${ }^{1}$ Laboratory Soil \& Vegetation, Botanical Institute, Neuchâtel University, Emile Argand Street, 11, CH-2007, \\ Neuchâtel, Switzerland. ${ }^{2}$ Group of Molecular Plant Physiology, Institute of Plant Biology, University of \\ Zürich, CH-8008, Zürich, Switzerland. ${ }^{3}$ Group of Plant Nutrition, Institute of Plant Sciences Eschikon, ETH \\ Zürich, CH-8315, Lindau, Switzerland. ${ }^{4}$ Laboratory of Geochemistry, Sedimentology and Mineralogy, \\ Geological Institute, Neuchâtel University, CH-2007, Neuchâtel, Switzerland. ${ }^{5}$ Corresponding author*
}

Received 3 October 2005. Accepted in revised form 25 January 2006

Key words: cluster roots, organic acids, phosphatases, phosphorus (P) acquisition, rhizosphere, white lupin (Lupinus albus L.)

\begin{abstract}
When grown in soils with sparingly available phosphorus (P), white lupin (Lupinus albus L.) forms special root structures, called cluster roots, which secrete large amounts of organic acids and concomitantly acidify the rhizosphere. Many studies dealing with the understanding of this $\mathrm{P}$ acquisition strategy have been performed in short time experiments either in hydroponic cultures or in small microcosm designs with sand or sand:soil mixtures. In the present study, we applied an experimental design which came nearer to the natural field conditions: we performed a one-year experiment on large microcosms containing $7 \mathrm{~kg}$ of soil and allowing separation of rhizosphere soil and bulk soil. We planted six successive generations of lupins and analysed $\mathrm{P}$ uptake, organic $\mathrm{P}$ desorption, phosphatase activities and organic acid concentrations in different soil samples along a spatio-temporal gradient. We compared the rhizosphere soil samples of cluster (RSC) and non-cluster roots (RSNC) as well as the bulk soil (BS) samples. A total shoot biomass of $55.69 \pm 1.51 \mathrm{~g}$ (d.w.) $\mathrm{y}^{-1}$ was produced and $\mathrm{P}$ uptake reached $220.59 \pm 5.99 \mathrm{mg} \mathrm{y}^{-1}$. More $\mathrm{P}$ was desorbed from RSC than from RSNC or BS $(P<0.05)$. RSC and RSNC showed a higher activity of acid and alkaline phosphatases than BS samples and a higher acid phosphatase activity was observed in RSC than in RSNC throughout the one-year experiment. Fumarate was the most abundant organic acid in all rhizosphere soil samples. Citrate was only present in detectable amounts in RSC while malate and fumarate were recovered from both RSC and RSNC. Almost no organic acids could be detected in the BS samples. Our results demonstrated that over a one-year cultivation period in the absence of an external $\mathrm{P}$ supply, white lupin was able to acquire phosphate from the soil and that the processes leading to this $\mathrm{P}$ uptake took place preferentially in the rhizosphere of cluster roots.
\end{abstract}

\section{Introduction}

In soils, phosphorus (P) availability is usually low. The two main forms of $\mathrm{P}$ are the adsorbed and precipitated inorganic phosphates, which

\footnotetext{
*FAX No: + 41(0)32-718-2231.
}

E-mail: claire.lebayon@unine.ch form complexes with $\mathrm{Ca}, \mathrm{Fe}$ or $\mathrm{Al}$, and the phosphate covalently bound to organic molecules. The only form of $\mathrm{P}$ available to plants is the inorganic phosphate present in the soil solution, which rarely exceeds $10 \mu \mathrm{M}$ (Schachtman et al., 1998). As a consequence, $P$ deficiency is one of the major limitations for crop production in many tropical and sub-tropical agroecosystems 
(Fairhust et al., 1999). Moreover, it has been estimated that inexpensive sources of rock $\mathrm{P}$ used as fertilizers might be depleted very soon, in a time range of $60-80$ years (Vance, 2001) and $P$ deficiency problems would then no longer be restricted to the tropical and subtropical agricultural context. To cope with this problem of low $\mathrm{P}$ availability in soils, plants have developed various strategies for efficient $\mathrm{P}$ acquisition, like (i) extensive root formation, (ii) association with mycorrhizal fungi (Abbott and Robson, 1982; Azaizeh et al., 1995; Khaliq and Sanders, 2000), (iii) secretion of organic acids (Jones, 1998) and phosphatases (Gaume et al., 2001), (iv) increased expression of high-affinity $\mathrm{P}$ transporters (Liu et al., 2001) or (v) the development of specialized roots structures known as cluster roots (Keerthisinghe et al., 1998; Lamont, 2003; Neumann and Martinoia, 2002; Purnell, 1960). White lupin (Lupinus albus L.) is the sole cluster root forming species of agricultural importance and is often used as a model plant for studying cluster root formation and secretion physiology. Cluster roots may represent more than $60 \%$ of the total root biomass (Keerthisinghe et al., 1998) and in comparison with non-cluster roots, they may increase the surface area by a factor of over 140 times per length unit and the volume of soil explored by 288 times per unit length (Lamont, 2003). This large surface-to-volume ratio improves the efficiency of solubilisation processes and nutrient uptake. Cluster roots are known to exude large amounts of low-molecular-weight organic anions, especially citrate, which enhances the availability of $\mathrm{P}$ to the plants (Dinkelaker et al., 1989; Gardner et al., 1983; Gerke et al., 1994). At the cellular level, Jones (1998) hypothesized two main routes of organic acid efflux from roots to the soil solution: (i) a slow passive diffusion across the lipid bilayer and, (ii) an efflux through a plasma membrane channel protein. In white lupin, carboxylates are secreted in the unprotonated form through recently identified channels (Sasaki et al., 2004; Zhang et al., 2004), whereas acidification is due to the activation of the plasma membrane proton pump (Yan et al., 2002). Depending on the dissociation properties and number of the carboxylic groups, organic anions may complex metal cations like $\mathrm{Al}^{3+}$, $\mathrm{Fe}^{3+}$ in acid soils and/or $\mathrm{Ca}^{2+}$ and $\mathrm{Mg}^{2+}$ in alkaline soils. In this context, Gardner et al.
(1983) suggested that ferric-hydroxyl-P-citrate complexes may be formed and then diffuse to the root surface where reducing agents would liberate the P. Alternatively, ligand exchange of $\mathrm{P}$ by citrate may also occur (Gerke et al., 1994). Further, root clusters may secrete enzymes into the rhizosphere, especially acid phosphatases that hydrolyze organic P (Gilbert et al., 1999; Wasaki et al., 1999, 2003). All these processes are involved in $\mathrm{P}$ mobilization and white lupin thus takes up $\mathrm{P}$ not only from the pool normally available to plants, but also from the stable residual soil P fractions (Kamh et al., 1999) that cannot be used by other plants like soybean (Braum and Helmke, 1995).

Many studies have focused on P nutrition and some of them were conducted using the hydroponic system for a better understanding of the processes involved (Hagström et al., 2001; Penazola et al., 2002; Sas et al., 2001; Wasaki et al., 2003). The use of sand cultures (Liu et al., 2001) and mixtures of sand and soil $(4: 1, \mathrm{Cu}$ et al., 2005; 1:1, Watt and Evans, 2003) constituted the next step, with a solid substrate but still quite far away from field conditions. A further important progress was to work with a whole soil matrix, and this was performed by using several experimental designs like rhizoboxes (Moritsuka et al., 2000), small pots filled with $450-800 \mathrm{~g}$ soil (Braume and Helmke, 1995) and plastic bags containing around $4 \mathrm{~kg}$ soil (Wouterlood et al., 2004). Larger experimental pots made of $10-\mathrm{cm}$ diameter PVC pipe and $60-\mathrm{cm}$ tall were used by Cavigelli and Thien (2003), and Bolland (1997) worked in the field on plots $1.4 \mathrm{~m}$ wide and $5 \mathrm{~m}$ long. Another important issue when studying plant nutrition is the length of the cultivation time. In most studies, short-time experiments were conducted (17 days, Moritsuka et al., 2000; 18 days, Gaume et al., 2001; 35 days, Watt and Evans, 2003; 42 days, $\mathrm{Cu}$ et al., 2005), whereas longer time scales, were used only in a few cases (from 57 to 64 days, Braume and Helmke, 1995; from 127 to 224 days, Bolland, 1997).

Sufficiently large systems and longer time spans of experiments are both needed for a more realistic view of the processes involved in the transfer of nutrients from soil to plant. An intermediate design between hydroponic systems/small pots in the laboratory and cultivated plots in the field is needed for a better understanding of the processes 
involved and this would enable a further extrapolation and/or modelling of results to the whole agroecosystem level. It is for these reasons that we conducted a one-year experiment in microcosms containing $7 \mathrm{~kg}$ of soil allowing quantification of transfer of soil phosphate to the plants from different root distances (comparing the uptake from rhizosphere soil vs. bulk soil). We used white lupin as a model plant and investigated temporary changes in soil organic and inorganic $\mathrm{P}$ pools, as well as secretion of phosphatases and organic acids by cluster and non-cluster roots. Even though white lupin reaches maturity in 224 days under field conditions (Bolland, 1997), the flowering stage of the plants under our experimental conditions was reached already 60 days after sowing, probably due to long day period $(16 \mathrm{~h})$ and the high light intensity. Therefore, six generations of lupin were consecutively planted to cover the time span of 1 year. This setup allowed us to gain deeper insights into rhizosphere processes than a single generation of plant cultivation since the effects were magnified by continuous cropping of the soil.

\section{Materials and methods}

\section{Experimental setup}

Microcosms (Figure 1) were used in this study, designed after 'Starpots' (Jansa et al., 2003) and consisting of a central PVC tube $(15 \mathrm{~cm}$ internal diameter and $35 \mathrm{~cm}$ height) and four small side arms (4 cm diameter and $20 \mathrm{~cm}$ length). Root penetration from the central tube to the side arms was prevented by a $25 \mu$ m-nylon mesh (Nitex 03-25/19, Sefar, Rüschlikon, Switzerland) between the side arms and the central tube (Figure 1). This system allows for the separation of roots from the side arms, although root hairs can pass through the nylon mesh because of their small diameter (Dittmer, 1949). These microcosms were filled with chromic luvisol $(5-30 \mathrm{~cm}$, Ap horizon) that had been regularly cropped with wheat (Corcelles-Concise, VD, Switzerland). This soil contained $50 \%$ sand, $30 \%$ silt, $20 \%$ clay, $0.97 \%$ organic carbon, $0.31 \%$ mineral carbon, ratio carbon:nitrogen $(\mathrm{C} / \mathrm{N})$ : 11.8, $\mathrm{pH}_{\mathrm{H}_{2} \mathrm{O}}$ :

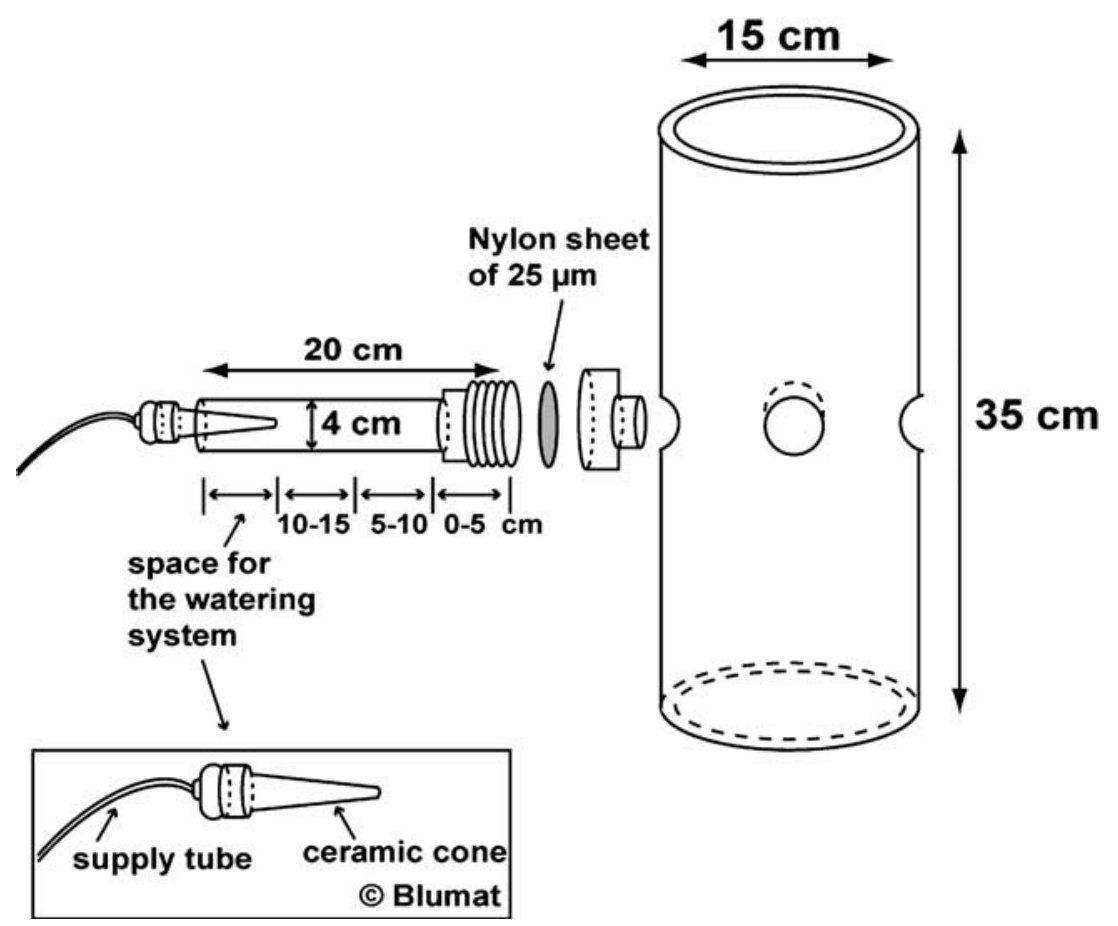

Figure 1. Scheme of a microcosm composed of a central PVC tube and four side arms. A nylon mesh of $25 \mu \mathrm{m}$ was inserted between each arm and the central tube. The side arm watering system is described (Blumat@). Soil collection sites in the arms are indicated. 
7.8, $\mathrm{pH}_{\mathrm{KCl}}: 7.02,1407.8( \pm 74.2) \mathrm{mg} \mathrm{kg}^{-1}$ total $\mathrm{P}$ colorimetrically measured following a Kjeldahl oxidation. The soil was air-dried after collecting in the field and sieved through a $2 \mathrm{~mm}$ mesh, and remoistened to $20 \%$ water content (w:w) prior to filling the microcosms at a bulk density of $1.35 \mathrm{~g} \mathrm{~cm}^{-3}$. Side arms were also filled with the same soil, and a manual watering system with a ceramic cone (Blumat $\odot$, Tensio-Technik, Geisenheim, Germany) was put at the end of each side arm (in the portion from 15 to $20 \mathrm{~cm}$ ) to promote water penetration. Seeds of white lupin (Lupinus albus L. cv. Amiga, Südwestdeutsche Saatzucht, Rastatt, Germany) were incubated overnight in aerated deionised water before being placed in between filter paper sheets moistened with $0.2 \mathrm{mM} \mathrm{CaSO}_{4}$ for 4 days in the dark and 1 day in the light. Four seeds were planted into the central tube of each microcosm.

\section{Experimental design and growth conditions}

Forty-eight microcosms were prepared and half of them were planted with lupin and half left unplanted. All microcosms were kept in a growth chamber (Normoflex, KR 11C/200S10, Schaller Uto AG, Bern, Switzerland) under the following conditions: photoperiod 16/8 h (day/night), temperature $24 / 20^{\circ} \mathrm{C}$ (day/night), $50 \%$ humidity, daylight intensity 8000 lux (mixed fluorescent tubes, 36W 830 and 36W 840). Three microcosms of each treatment were then harvested at each of the eight sampling dates, namely after 1 , 2, 3, 4, 5, 6, 9 and 12 months after sowing. For watering (both in sides arms and at the top of microcosms), we used a nutrient solution without $\mathrm{P}$ containing (in $\left.\mathrm{mg}^{-1}\right): \mathrm{Ca}\left(\mathrm{NO}_{3}\right)_{2} \cdot 4 \mathrm{H}_{2} \mathrm{O}$ (118), $\mathrm{K}_{2} \mathrm{SO}_{4}$ (32.6), $\mathrm{MgSO}_{4} \cdot 7 \mathrm{H}_{2} \mathrm{O}$ (40), FeNaEDTA (3.67), $\mathrm{KCl}(0.93), \mathrm{H}_{3} \mathrm{BO}_{3}(0.46), \mathrm{MnSO}_{4} \cdot \mathrm{H}_{2} \mathrm{O}$ (0.42), $\mathrm{CuSO}_{4} \cdot 5 \mathrm{H}_{2} \mathrm{O}(0.06), \mathrm{ZnSO}_{4} \cdot 7 \mathrm{H}_{2} \mathrm{O}(0.072)$, $\mathrm{Mo}_{7} \mathrm{O}_{24}\left(\mathrm{NH}_{4}\right)_{6}(0.93)$. Over the growth period, no water leached from the microcosms.

\section{Harvest and sampling}

At the beginning of the lupin flowering state (after 60 days in our experimental conditions), shoot biomass of all plants was harvested, and new seeds (4 per microcosm) were planted into each microcosm to start the next generation. For the assessment of shoot biomass and P uptake by the continuously cropped lupins during the whole cultivation period (Figure 2), values were cumulated from one generation to the next for the microcosms undergoing more than one lupin generation (i.e. from month 3 to 12). At each of the eight sampling dates, six microcosms (three with lupin and three without plants) were harvested. Shoots of the four plants were pooled and dried at $40{ }^{\circ} \mathrm{C}$ to avoid carbon or nitrogen losses. Roots were collected from the central tubes of each of the microcosms (separately the cluster and non-cluster roots). Likewise, bulk soil samples (not adhering to roots) were collected from the central tubes. Amounts of both cluster and non-cluster roots were similar at each sampling date, and all roots were linked together. This indicates that roots collected at each sampling date originated from the living plants and that the older roots were decomposed. Rhizosphere soil (adhering to the roots) was gently shaken off the roots and sieved through $1 \mathrm{~mm}$ mesh. Fine roots were carefully removed from the sieved soil and a distinction was made between rhizosphere soil from cluster roots (RSC) and rhizosphere soil from non-cluster roots (RSNC). Three soil samples were obtained from the side arms, namely the portions at distances $0-5,5-10$ and $10-15 \mathrm{~cm}$ from the central tube. Samples from the same distances in the four different side arms were pooled. So, on our root-soil gradient ranging from the immediate root vicinity to the most distant soil, six different soil samples were collected: the rhizosphere soil of cluster roots (RSC) and non-cluster roots (RSNC), the bulk soil (BS) collected from the central cylinder (BS0) and the three sections from the side arms, 0-5 cm (BS5), 5-10 cm (BS10) and $10-15 \mathrm{~cm}$ (BS15). From each sample, one part was stored at $-80{ }^{\circ} \mathrm{C}$ for organic acids analysis, while another part was stored at $+4{ }^{\circ} \mathrm{C}$ for a maximum of 2 days for enzymatic assays. For $\mathrm{P}$ analysis, both soil and plant samples were dried at $40{ }^{\circ} \mathrm{C}$ for $48 \mathrm{~h}$.

\section{Soil phosphatases}

The analysis of phosphatase activity (phosphomonoesterase) was based on the release of paranitrophenol (stained in yellow) by the enzymes after soil incubation with para-nitrophenyl phos- 
phate as a substrate in a modified universal buffer MUB [pH 6.5 for the assay of acid phosphatase activity (AcPA), and $\mathrm{pH} 11$ for the assay of alkaline phosphatase activity (AkPA)], as described by Tabatabai and Bremner (1969). The reaction mixture contained $1 \mathrm{~g}$ soil to which $1 \mathrm{ml}$ para-nitrophenyl phosphate $\left(1 \mathrm{~g} \mathrm{l}^{-1}\right)$ and $0.25 \mathrm{ml}$ of toluene were added. After shaking and following the incubation for $1 \mathrm{~h}$ at $37^{\circ} \mathrm{C}$, the soil solution was filtered (Whatman $\mathrm{GF} / \mathrm{C}$ ) and the absorbance of the filtrate was measured at $400 \mathrm{~nm}$ (Spectrophotometer Libra S12, Biochrom, Biolabo SA, Châtel-St-Denis, Switzerland).

\section{Phosphorus in soil and plants}

Total $\mathrm{P}$ in both soil and plant samples was colorimetrically measured following a Kjeldahl oxidation. One gram of soil or $0.5 \mathrm{~g}$ dry weight (d.w.) plant biomass was put into a digestion tube (Büchi, Laboratoriums-Technik AG, Flawil, Switzerland) with two glass balls, a Kjeldahl tablet (Merck, VWR International, Nyon, Switzerland) and $12 \mathrm{ml}$ of $\mathrm{H}_{2} \mathrm{SO}_{4} 96 \%$. After digestion at $360{ }^{\circ} \mathrm{C}$ for $2 \mathrm{~h}$, samples were cooled and $60 \mathrm{ml}$ of de-ionized water were added. After filtration (512 1/2, Schleicher and Schuell AG, Riehen, Switzerland), $\mathrm{P}$ was determined at $880 \mathrm{~nm}$ using the molybdate procedure (Murphy and Riley, 1962). Organic $\mathrm{P}$ was assessed by igniting soil samples (1 g d.w.) in a muffle furnace at $550{ }^{\circ} \mathrm{C}$ for $1 \mathrm{~h}$ (modified from Anderson and Ingram, 1993). Both ignited and unignited samples were placed into propylene tubes and $50 \mathrm{ml}$ of $0.5 \mathrm{~N} \mathrm{H}_{2} \mathrm{SO}_{4}$ were added. After shaking the tubes overnight, samples were filtered $\left(512 \frac{1}{2}\right.$ filter type, low $\mathrm{P}$ content, pore diameter: $2 \mu \mathrm{m}$, Schleicher and Schuell, Switzerland) and $\mathrm{P}$ was determined as above. The difference in the acid extractable $\mathrm{P}$ of ignited and unignited samples provides an estimate of organic P. Extractable P (also called plant available $\mathrm{P}$ in the following text) was determined according to Olsen et al. (1954) by shaking $2.5 \mathrm{~g}$ of soil with $60 \mathrm{ml}$ of sodium bicarbonate $\mathrm{NaHCO}_{3} \quad(0.5 \mathrm{~N}, \quad \mathrm{pH}$ 8.5) for $30 \mathrm{~min}$. Phosphate was determined in the filtrate (512 1/2 filter type, low P content, pore diameter: $2 \mu \mathrm{m}$, Schleicher and Schuell, Switzerland) as above.

\section{Organic acids in soil}

Organic acids were extracted by shaking soil $(0.75 \mathrm{~g}$ fresh weight $)$ with $1.5 \mathrm{ml}$ sterilized de-ionized water for $30 \mathrm{~min}$ at $1400 \mathrm{rpm}$. Samples were then centrifuged for $5 \mathrm{~min}$ at $16,000 \times g$. The supernatant was filtered through $0.2 \mu \mathrm{m}$ syringe filters (Semadeni SA, Ostermundigen, Switzerland) and $600 \mu \mathrm{l}$ were dried at $50{ }^{\circ} \mathrm{C}$ in a speed-vac (Univapo $150 \mathrm{H}$, Uniequip, Martinsried, Deutschland). Samples were resuspended in distilled water and $100 \mu \mathrm{l}$ was analyzed by HPLC. Organic acids were separated on a cation-exchange column $\left(300 \times 7.8 \mathrm{~mm}, 10 \mu \mathrm{m}, \mathrm{H}^{+}\right.$ form, Benson, Reno, Nevada, USA) using isocratic elution with $20 \mathrm{mM} \quad \mathrm{H}_{2} \mathrm{SO}_{4}$ at $0.7 \mathrm{ml} \mathrm{min} \mathrm{mi}^{-1}$ and room temperature. Absorbance was monitored at $210 \mathrm{~nm}$. Calibration curves with standard organic acids (Fluka, Switzerland) were performed for quantification of the most abundant organic acids present in the analyzed samples.

\section{Statistical analysis}

Statistical analyses were performed in S-PLUS, version 6.1 (Insightful Corporation, Seattle, WA, USA). Data were tested for normality of distribution and homogeneity of variance (Kolmogorov-Smirnov test). The two-factor analyses of variance (ANOVAs) were performed to test the impact of the proximity of roots (rhizophere vs. non-rhizosphere soil) and the length of the growth period on total soil $\mathrm{P}$, organic $\mathrm{P}$, extractable $\mathrm{P}$, and organic acids in the different soil samples. For pairwise comparisons, we used Tukey-Kramer HSD tests (interval of confidence $95 \%$ ) and the Student's $t$-test for the organic acid data (interval of confidence: 95\%).

\section{Results}

\section{$P$ uptake by lupin}

Shoot biomass and total $\mathrm{P}$ contents (after subtracting the $\mathrm{P}$ contained in the original seeds) are shown in Figure 2 as cumulative values over the one-year experiment. Aboveground biomass production of lupin during the first two months of 
the experiment reached $10.27 \pm 1.12 \mathrm{~g}$ (aboveground biomass) (d.w.) per pot. Biomass production of about $80 \%$ was reached within 1 month of growth, and this resulted in the timeline of biomass plateauing at 2, 4 and 6 months (Figure 2).

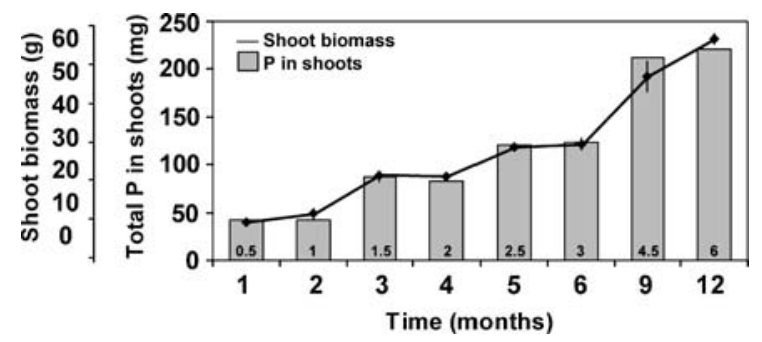

Figure 2. Mean values of dry weight of white lupin shoots per month (line) and mean values of total phosphorus (P) uptake (total $\mathrm{P}$ content minus original seed $\mathrm{P}$ ) in the shoots per month (bars). For microcosms undergoing more than one lupin generation (from month 3 to 12), data for all previous generations were cumulated per microcosm replicate and per date before the calculation of means and standard errors. Small numbers in the bars indicate the number of plant generations at each date (one generation corresponds to $60 \mathrm{~d}$ of cultivation).
In total, $55.69 \pm 1.51 \mathrm{~g} \mathrm{~d}$.w. were produced during 1 year of cropping. $\mathrm{P}$ uptake by lupin ( $\mathrm{P}$ content minus seed $\mathrm{P}, 2.93 \pm 0.36 \mathrm{mg} \mathrm{P}$ seed ${ }^{-1}$ ) followed the same pattern as the biomass throughout the experiment (Figure 2), with a total of $220.59 \pm 5.99 \mathrm{mg} \mathrm{P}$ extracted by the plants from the soil. This represents $2.62 \%$ of the total $\mathrm{P}$ present in the pot.

\section{Soil $P$}

For both rhizosphere and root-free soil fractions, the amounts of extractable $\mathrm{P}$ remained constant in the first 6 months of the experiment, and then decreased gradually (Figure 3a). More $\mathrm{P}$ was desorbed from the RSC than from the RSNC or BS15 soil fractions $(P<0.05$, Figure $3 \mathrm{a})$. A temporary decline in the soil organic $\mathrm{P}$ pool was observed in the RSC fraction, followed by a rise from month 2 to month 6 , and subsequent decline between 6 and 12 months of cultivation (Figure 3b). Except for the first month, RSC consistently showed the lowest
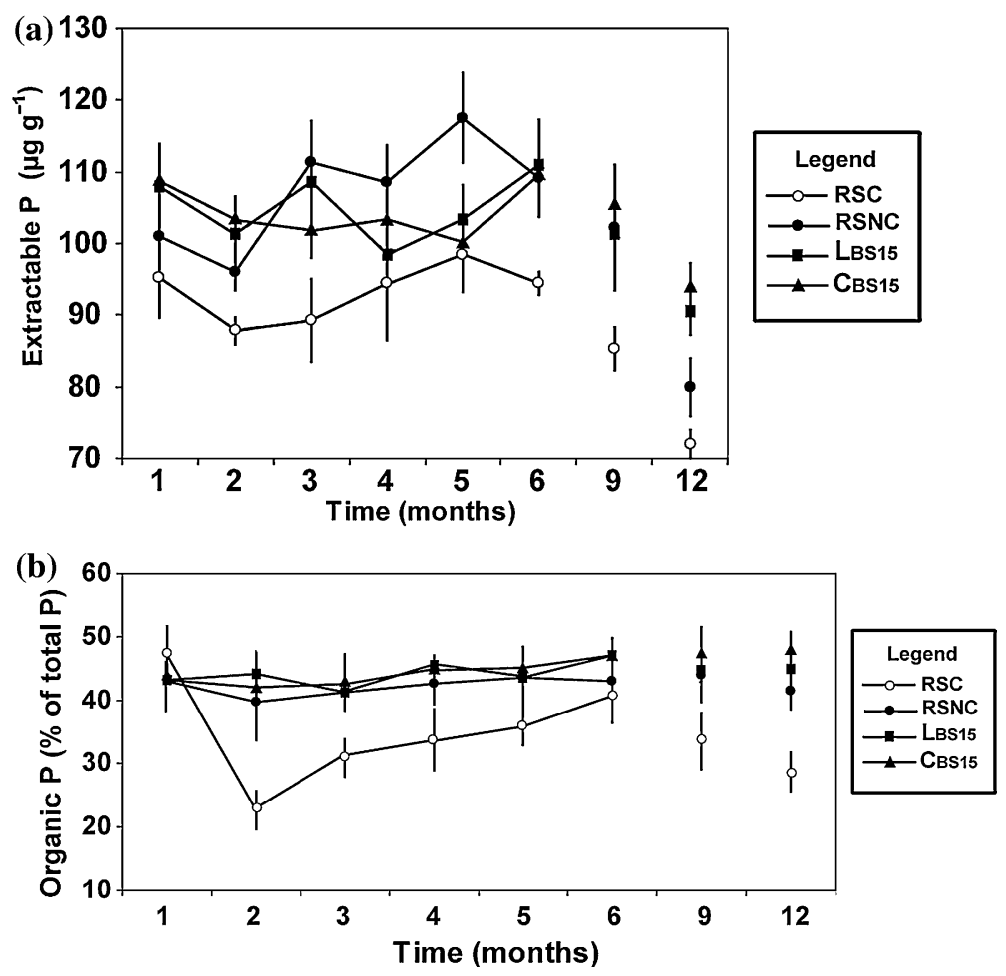

Figure 3. Soil bicarbonate extractable $\mathrm{P}$ (a) on a dry weight soil basis, and soil organic $\mathrm{P}$ (b) at different times from beginning of the experiment. $\mathrm{L}_{\mathrm{BS} 15}$ : soil from side arms of microcosms planted with lupin, 10-15 cm from roots; $\mathrm{C}_{\mathrm{BS} 15}$ : soil from side arms of microcosms without lupin; RSC: rhizosphere soil from cluster roots; RSNC: rhizosphere soil from non-cluster roots. Means and standard errors of means of three replicates are shown. 
levels of organic $\mathrm{P}(P<0.05)$ among the soil samples, suggesting that more organic $\mathrm{P}$ had been mineralized in RSC than in the other soil samples. In contrast to the differences observed between RSC and bulk soil samples, no significant differences between RSNC and bulk soil were observed, neither in organic $\mathrm{P}$ nor in extractable $\mathrm{P}$. This indicates that $\mathrm{P}$ acquisition was mostly taking place via the cluster roots. To investigate the possible underlying solubilisation and acquisition mechanisms in soil $\mathrm{P}$ pools, we analyzed phosphatase activities and organic acid levels.

\section{Phosphatase activities}

Both acid and alkaline phosphatase activities (AcPA and AkPA, respectively) were higher in RSC and RSNC soils than in BS15 soils from either planted or unplanted containers (Figure 4).
Acid phosphatase was more active in RSC than in RSNC soil $(P<0.05$, Figure $4 \mathrm{a})$, being 3.5 times higher in $\operatorname{RSC}\left(35.6 \mu \mathrm{mol} \mathrm{g}^{-1} \mathrm{~h}^{-1}\right)$ than in RSNC $\left(10.8 \mu \mathrm{mol} \mathrm{g}^{-1} \mathrm{~h}^{-1}\right)$ after 2 months of cultivation. Over the time, AcPA showed a strong negative correlation with organic $\mathrm{P}$ (Spearman rho $=-0.93, P=0.02$ ). This correlation fits with the known hydrolysis mechanism of the organic $\mathrm{P}$ and indicates that phosphatase activity may well account for the $\mathrm{P}$ acquisition of white lupin, as shown in Figure 2. AkPA was significantly lower than AcPA (Figure 4b). However, a significant difference between rhizosphere soil and bulk soil fractions was still observed during the first 6 months $(P<0.05)$.

\section{Organic acids}

Fumarate was the most abundant organic acid in the soil samples, followed by malate and citrate
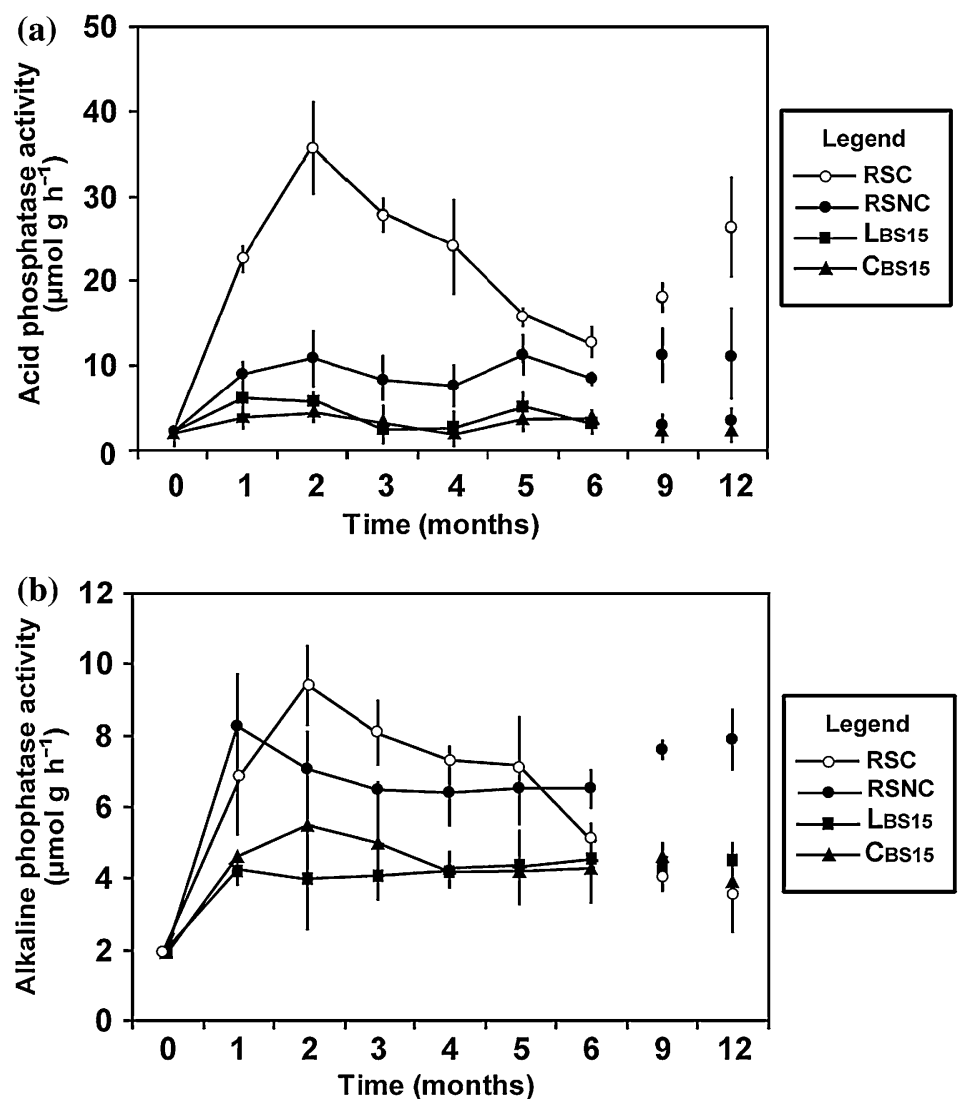

Figure 4. Phosphatase activities in soil (on dry weight basis). (a) Acid phosphatase (pH 6.5), and (b) alkaline phosphatase (pH 11). $\mathrm{L}_{\mathrm{BS} 15}$ : soil from side arms of microcosms planted with lupin, $10-15 \mathrm{~cm}$ from roots; $\mathrm{C}_{\mathrm{BS} 15}$ : soil from side arms of microcosms without lupin; RSC: rhizosphere soil from cluster roots; RSNC: rhizosphere soil from non-cluster roots. Means and standard errors of means of three replicates are shown. 
(Figure 5). Significantly higher amounts of the three major organic acids (fumarate, citrate and malate) were found in pots planted with lupin than in the unplanted pots $(P<0.05$, data not shown). Traces of other organic acids like acetate or succinate were also found in the samples (data not shown). There was a high variability in the organic acid concentrations with time, especially in the rhizosphere soil samples. High amounts were found after 2 months (first lupin generation) and after 12 months (sixth lupin generation). In RSNC, organic acid production was low 9 months after the beginning of the experiment (Figure 5), which corresponds to a sampling date, where lupins were $30 \mathrm{~d}$ old, and not $60 \mathrm{~d}$, as was the case otherwise. Citrate was much more abundant in RSC than in RSNC $(P<0.05)$. In contrast, malate and fumarate were present in significantly higher amounts in RSNC $(P<0.05)$. As expected, almost no organic acids could be detected in the bulk soil or in the $10-15 \mathrm{~cm}$ section of the microcosm side-arms, except for little amounts of fumarate detected at some sampling dates. However, fumarate was also found in control pots (Figure $6 \mathrm{c}$ ), indicating that its presence cannot be directly related to root secretion activity

\section{Soil after 1 year of lupin cultivation}

Figure 6 describes the situation after 1 year and shows the results for all locations along the rootsoil gradient. For extractable P (Figure 6a) a difference between lupin and control pots was observed for BS0 and BS5 $(P<0.05)$, but this difference disappeared with increasing distance from the roots. The high level of extractable $\mathrm{P}$ in BS5 could be explained by the fact that the nylon mesh could act as a physical support for plant roots and/or bacteria; thus, higher root exudation and/or bacterial secretion could occur at this place, leading to greater phosphatase activities and consequently a higher organic $\mathrm{P}$ mineralization than in the distant soil BS0. In addition, despite the low values of the enzymatic activities in the bulk soil samples, AkPA was higher in BS0 in microcosms planted with lupin compared to control pots $(P<0.05)$ but this difference also disappeared with distance from the root system (Figure 6b). In contrast, a clear rhizosphere effect could be observed in all the three parameters studied (Figure 6a, b and c): (i) lower values of extractable $\mathrm{P}$ were measured in RSC and RSNC than in BS0, BS5, BS10 and BS15 $(P<0.05)$; (ii) except for AkPA

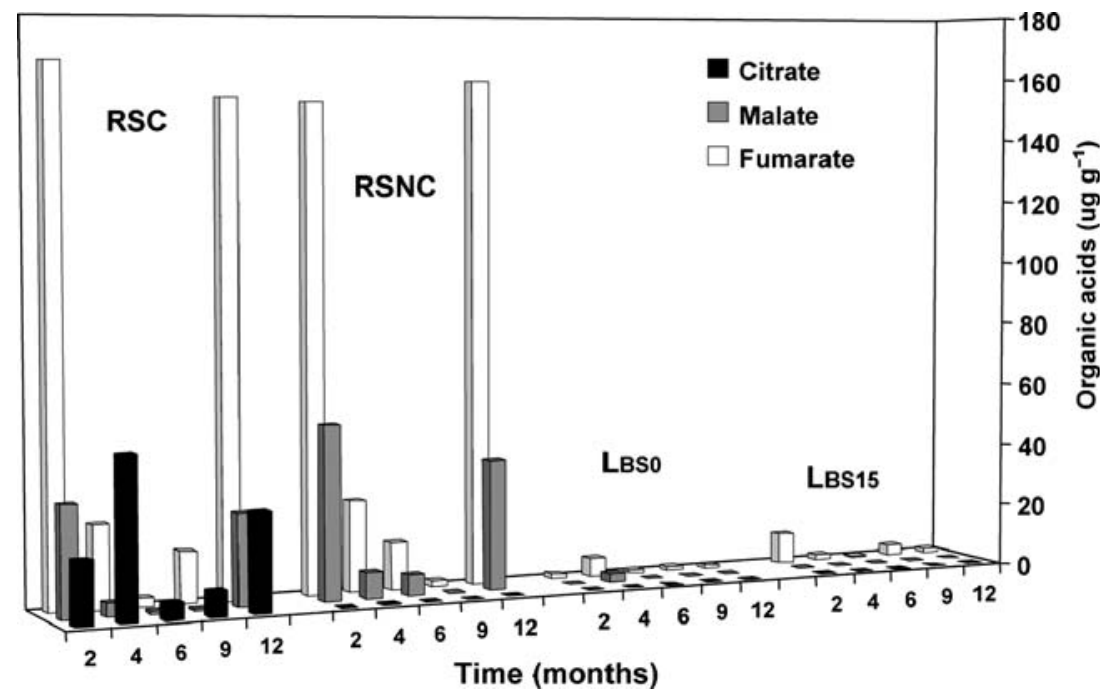

Figure 5. Concentrations of organic acids in soil (on dry weight basis): citrate (black), malate (grey) and fumarate (white) in the different soil fractions from microcosms planted with lupin. RSC: rhizosphere soil of cluster roots; RSNC: rhizosphere soil of noncluster roots; $\mathrm{L}_{\mathrm{BS} 0}$ : bulk soil from central cylinder of microcosms. $\mathrm{L}_{\mathrm{BS} 15}$ : soil from side arms of the microcosms planted with lupin, $10-15 \mathrm{~cm}$ from roots. Bars represent means of three replicates. 

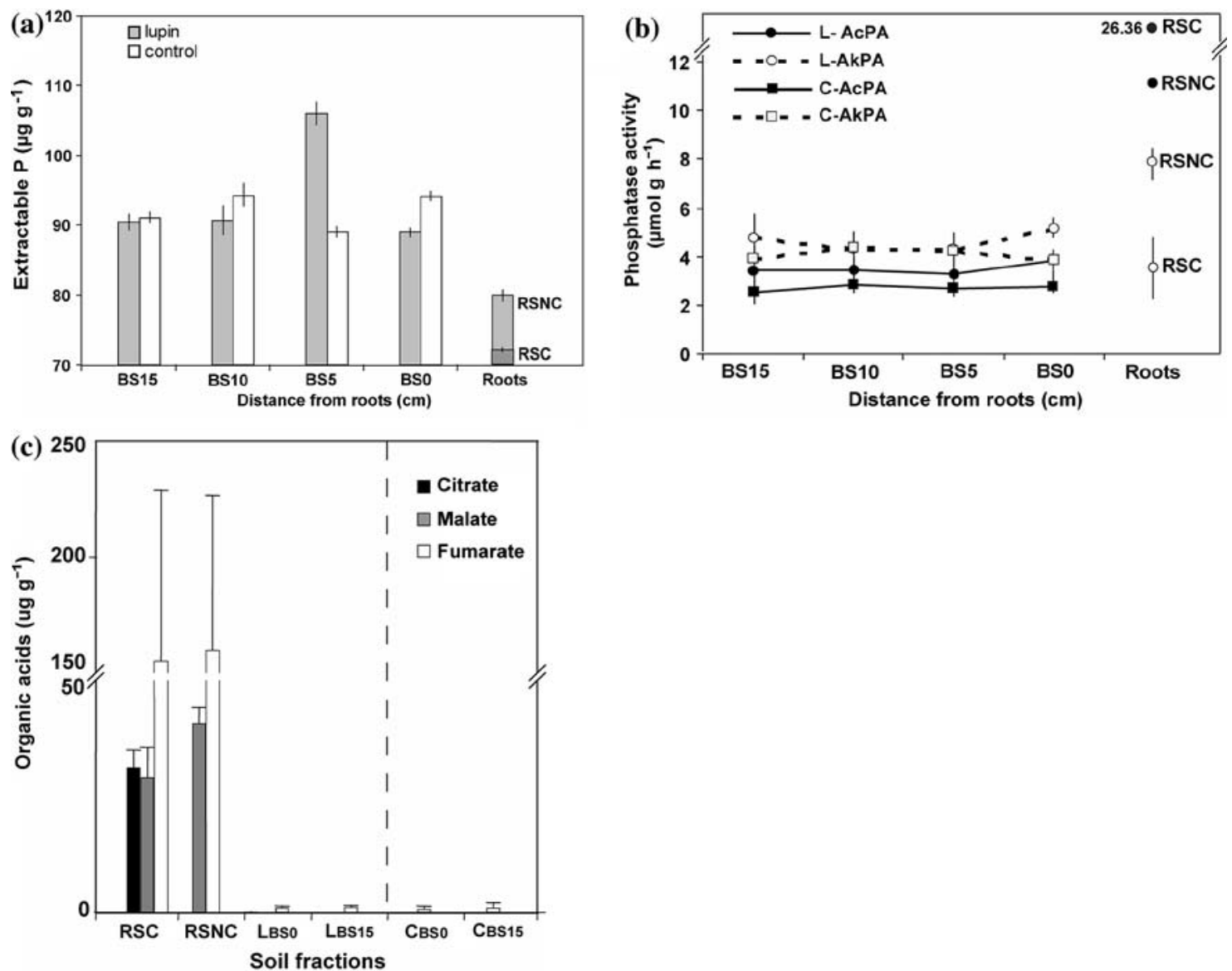

Figure 6. Soil bicarbonate extractable P (a), phosphatase activity (b) and organic acid concentrations (c) after 1 year of cultivation. (a): Soil bicarbonate extractable P. Grey and white bars indicate microcosms planted with lupin and unplanted ones, respectively. Soil from 0 to 5 (BS5), 5 to 10 (BS10), and 10 to 15 (BS15) cm from the roots was obtained from the side arms of the microcosms. BS0: bulk soil from the central cylinder of microcosms. RSC: rhizosphere soil from cluster roots. RSNC: rhizosphere soil from non-cluster roots. Acid (AcPA, solid lines, closed symbols) and alkaline (AkPA, dashed lines, open symbols) phosphatase activities in soil (on dry weight basis) in microcosms with and without lupin (circles and squares, respectively). The value of AcPA is indicated on the figure (26.36) for RSC. For the legend for BS0, BS5, BS10, BS15, RSNC and RSC, see (a). (c): Concentrations of citrate (black), malate (grey) and fumarate (white) in soil (on dry weight basis) planted with lupin or not. RSC: rhizosphere soil of cluster roots. RSNC: rhizosphere soil of non-cluster roots. $\mathrm{L}_{\mathrm{BS} 0}$ and $\mathrm{C}_{\mathrm{BS}} 0$ : bulk soil from the central cylinder of microcosms planted or not, respectively. $\mathrm{L}_{\mathrm{BS} 15}$ and $\mathrm{C}_{\mathrm{BS} 15}$ : soil from side arms of microcosms planted or not with lupin, respectively. Means and standard errors of means of three replicates are shown.

in RSC, phosphatase activities were in general higher near the roots than far from them (Figure $6 \mathrm{~b}, P<0.05$ ) and (iii) the same trend was observed for organic acid concentrations (Figure 6c, $P<0.05)$. As compared to the rhizosphere of non-cluster roots, the soil sampled from the rhizosphere of cluster roots displayed a lower extractable P level, a higher acid phosphatase activity and a greater concentration of citrate (Figure $6 \mathrm{a}, \mathrm{b}$ and $\mathrm{c}$ ).

\section{Discussion}

The present study was conducted to monitor the $\mathrm{P}$ dynamics (sorption/desorption and acquisition by plants) in an experimental setup based on the Starpot model (Jansa et al., 2003) which enabled us to come a step nearer to the natural field conditions. The originality of this design was the implementation of root-free compartments in our microcosms allowing us to define three levels of root proximity, 
(i) rhizosphere soil, (ii) bulk soil (i.e. non-adhering to roots) from the central compartment of microcosms and, (iii) bulk soil from the side-arms, where a complete absence of roots was guaranteed. We followed the changes in $\mathrm{P}$ uptake, extractable and organic P pools, phosphatase activities as well as organic acids during 1 year of cultivation and we showed a clear spatio-temporal evolution of most of the measured variables.

Shoot biomass reached $55.69 \pm 1.51$ g (d.w.) per microcosm at the end of the year. Despite the supply of iron and zinc through the nutrient solution and despite the relatively high amounts of bicarbonate extractable $\mathrm{P}$ in the original soil, white lupins produced a significant quantity of cluster roots, especially at the end of the one-year experiment. Our results show that P-adequate plants also form cluster roots as previously demonstrated by Shen et al. (2003) who supported the hypothesis that a partial depletion of available $\mathrm{P}$ over time could have induced $\mathrm{P}$ deficiency and enhanced formation of cluster roots. In our study, the low amounts of organic $\mathrm{P}$ and bicarbonate extractable $\mathrm{P}$, and conversely the high phosphatase activities and the significant release of organic acids near the roots after a year confirmed this hypothesis.

Over the course of experiment, there was a clear effect of plant generation, especially in the rhizosphere soil samples. Particularly after month 2 and 12, an efficient $\mathrm{P}$ acquisition mechanism is reflected by the very low $\mathrm{NaHCO}_{3}$ extractable $\mathrm{P}$ levels left around the roots of white lupin, and especially around cluster roots (Figures $3 \mathrm{a}$ and 6a). The low extractable $\mathrm{P}$ concentration in the rhizosphere soil fraction at month 2 may be due to different reasons: first, it may be linked to a high general microbial activity (which was also reflected by a high urease activity, see below). This higher bacterial activity might have been stimulated by the enhanced secretion of organic acids in the rhizosphere of both cluster and non-cluster roots, as shown in Figure 5 and it could have led to higher bacterial $\mathrm{P}$ uptake in this rhizosphere environment. Another possible explanation is the fact that after two months, the first generation had completed its growth and took up phosphate, part of which would remain in the root system and, after mineralization by the microcosm microflora, return to the soil and benefit to the next generation, explaining the higher remaining extractable $\mathrm{P}$ at the following harvest dates. Phosphatase activities (Figures 4 and 6b), as well as the high amounts of organic acids (Figures 5 and 6c), revealed a complementary strategy to acquire $\mathrm{P}$ from both the organic and the inorganic pools. Thus, without addition of exogenous $\mathrm{P}$, white lupins could still find some $\mathrm{P}$ in the soil to take up until the end of the experiment.

We found that, in addition to the wellknown secretion of organic acids, which was clearly demonstrated previously in hydroponic systems and confirmed in our study, phosphatases also played a major role in $\mathrm{P}$ acquisition. Again, we were able to confirm in an experimental situation which approaches the real field conditions, the findings previously discovered and studied in hydroponic cultures (Gaume et al., 2001; Wasaki et al., 2003). A qualitative in vivo analysis of phosphatase activity was made in a loamy soil by Dinkelaker and Marschner (1992). Our experiment is, to our knowledge, the first quantitative measure of both acid and alkaline phosphatase activities in the rhizosphere soil of the cluster roots of white lupin. Phosphatase activities were higher in the rhizosphere soil than in the bulk soil. In the rhizosphere of cluster roots, the high activity of AcPA showed a strong negative correlation with organic $\mathrm{P}$ (expressed as a percentage of total $\mathrm{P}$ ) over the cultivation period. This suggests an intense hydrolysis of organic $\mathrm{P}$ over the year resulting in a considerable release of available $\mathrm{P}$ in the vicinity of cluster roots. The first peak of AcPA after two months of incubation (Figure 4a), which was correlated to a strong decrease in organic $\mathrm{P}$ contents (expressed as a percentage of total $\mathrm{P}$ ) at the same sampling time, may be due either to a generally high secretion of root exudates including phosphatases, or to an intense microbial growth in response to these root exudates, and the production by these microbes of phosphatases. This particular behaviour at the beginning of the experiment may be due to a necessary adjustment of the experimental system, since air-drying, sieving and remoistening the soil had certainly disturbed the microflora and microfauna living in the soil. This was confirmed by an additional measure of urease activity that was strongest at month 2 (data 
not shown). It appears that a certain amount of time is required for the system to reach a new equilibrium. The high enzyme activity observed after twelve months may reflect an actual need for $\mathrm{P}$ for the white lupin growth. We observed also the presence of AcPA in $\mathrm{RSNC}$, leading to a significant desorption of $\mathrm{P}$ in the proximity of non-cluster roots over the time. This is in line with the findings of Wasaki et al. $(1999,2003)$ who showed that not only cluster roots but the whole root system could secrete acid phosphatases. These authors showed that the activity of AcPA was highest in lupin grown under $\mathrm{P}$ deficiency and that the expression of the gene encoding this enzyme was induced by a decrease in internal $\mathrm{P}$ concentrations (Wasaki et al., 2003). The same observation was made by Gilbert et al. (1999), who found an enhanced AcPA activity in both root extracts and root exudates of white lupins grown in P-deficient conditions. Moreover, these authors also showed that under $\mathrm{P}$ deficiency, an additional isoform of AcPA was produced and secreted by white lupin roots. This additional isoform was present in far greater amounts in the roots and root exudates of cluster roots, as compared to non-cluster roots. Releasing acid phosphatases is not restricted to lupin roots and this phenomenon was also demonstrated for P-deficient maize in hydroponic culture (Gaume et al., 2001). In addition, Asmar et al. (1995) showed higher rhizosphere phosphatase activity, which might increase mobilization and depletion of soil organic $P$ in barley. While many authors only analyzed AcPA, we also investigated the alkaline form of the enzyme and we found that the activity was smaller by a factor of four both in RSC and RSNC, but significantly higher compared to control soil. This original result leads us to suggest that not only AcPA but also AkPA may contribute to the improvement of $\mathrm{P}$ desorption from the soil matrix. However, the stability of acid and alkaline phosphatases (4.5-6 and 9-10 as $\mathrm{pH}$ optima, respectively; Alef et al., 1995) is known to depend on the soil pH (Eivazi and Tabatabai, 1977; Tabatabai 1994) and since white lupins are usually growing in acidic soils, acid phosphatase may be more relevant than alkaline phosphatase in the desorption of organic P.
In addition to phosphatases, release of organic acids from roots is another important mechanism which increases $\mathrm{P}$ acquisition by plants (Dinkelaker et al., 1989; Jones, 1998). Citrate and malate have been reported to be secreted from white lupin cluster roots in a growth-stage dependent manner (Massonneau et al., 2001; Neumann et al., 1999, 2000). For experimental reasons, the different growth stages could not be differentiated in our system, but the presence of citrate and not only malate indicates that mature cluster roots were also harvested here. In our study, fumarate was more abundant than citrate and malate. Fumarate has previously been observed in the root exudates of lupin: Cawthray (2003) found comparable amounts of fumarate, malate and citrate in exudates of soil-grown white lupin, while Neumann and Römheld (1999) found traces of fumarate in root exudates of white lupin, as well as in wheat, tomato and chickpea. In our study, highly variable fumarate concentrations did not allow to definitely conclude about a possible involvement of this carboxylate in $\mathrm{P}$ acquisition. Apart from one study (Imas et al., 1997), where fumarate was shown to increase exponentially in tomato root exudates under $\mathrm{P}$ deficiency, the possible involvement of fumarate is much less well documented than the involvement of citrate and malate.

The low amounts of organic acids found in the soil samples, i.e. several micrograms compared to several milligrams in the roots themselves (data not shown), may be explained by their rapid sorption on the soil's solid phase which is highly $\mathrm{pH}$ dependent as revealed by Jones and Brassington (1998). In our case, carboxylates were retrieved in significant amounts only from rhizosphere soil fractions, certainly due to the root secretion activity. In addition, the microbial degradation rates of these P-chelating agents may be highly variable and stronger far away from roots. In the case of white lupin, the $\mathrm{pH}$ strongly decreases in the direct proximity of cluster roots, which is due to a proton extrusion that occurs concomitantly with the secretion of citrate (Sas et al., 2001). In addition to the role of these protons in maintaining charge balance through compensation of the negative charges of the secreted organic anions, this $\mathrm{pH}$ decrease might also play an indirect role in reducing microbial consumption of citrate and malate. We have previously shown that in the 
rhizosphere of cluster roots, bacterial abundance is significantly reduced in the proximity of citrate secreting root parts (Weisskopf et al., 2005) and this supports the hypothesis that the decrease of $\mathrm{pH}$ may partly be responsible for the lower abundance of bacteria at the stage where citrate secretion takes place.

In conclusion, our results showed that the rhizosphere of white lupin, and especially the vicinity of cluster roots was characterized by (i) important mineralisation processes over the year of cultivation (ii), high acid phosphatase activity as well as alkaline phosphatase activity, demonstrated to our knowledge for the first time in white lupin rhizosphere and, (iii) high levels of citrate and malate, with citrate only present in the rhizosphere of cluster roots. As previously reported by Gilbert et al. (1999), white lupin develops several coordinated adaptative strategies to P-deficient conditions that such a one year study in microcosms could help to understand at a large spatio-temporal scale. Our results showed that the soil collected in the central tube was also influenced by the roots, assessing the problem of root proximity in small pots mentioned by Gregory (2004). The next step of this research would be the use of mesocoms in the field under annual variations of temperature, natural night/day cycles and rainfall events for a better approach of agroecosystem functioning.

\section{Acknowledgments}

The authors thank gratefully the National Centre of Competence in Research (NCCR) Plant Survival, a program from the Swiss National Science Foundation, for the financial support of this research. We also thank M. Gratier for the easy access to the experimental plot where the soil was collected, as well as L. Nemitz, L. MathysPaganuzzi and N. Fahrni for their technical help. We also gratefully acknowledge the anonymous reviewers for providing critical comments that helped to improve this manuscript.

\section{References}

Abbott L K and Robson A D 1982 The role of vesicular arbuscular mycorrhizal fungi in agriculture and the selection of fungi for inoculation. Aust. J. Agric. Res. 33, 389-408.
Alef K, Nannipieri P and Trazar-Cepeda C 1995 Phosphatase activity. In Methods in Applied Soil Microbiology and Biochemistry. Eds. K Alef and P Nannipieri. pp. 335-344. Academic Press, London.

Anderson J M and Ingram J S I 1993 Tropical Soil Biology and Fertility - A Handbook of Methods. 2CAB International, Oxford $221 \mathrm{pp}$.

Asmar F, Gahoonia T S and Nielsen N E 1995 Barley genotypes differ in extra-cellular phosphatase activity and depletion of organic phosphorus from rhizosphere soil. Plant Soil 172, 117-122.

Azaizeh H A, Marschner H, Römheld V and Wittenmayer L 1995 Effects of vesicular-arbuscular mycorrhizal fungus and other soil microorganisms on growth, mineral nutrient acquisition and root exudation of soil-grown maize plants. Mycorrhiza 5, 321-327.

Bolland M D A 1997 Comparative phosphorus requirement of four lupin species. J. Plant Nutri. 20, 1239-1253.

Braum S M and Helmke P A 1995 White lupin utilizes soil phosphorus that is unavailable to soybean. Plant Soil 176, 95-100.

Cavigelli M A and Thien S J 2003 Phosphorus bioavailability following incorporation of green manure crops. Soil Sci. Soc. Am. J. 67, 1186-1194.

Cawthray G R 2003 An improved reversed-phase liquid chromatographic method for the analysis of low-molecular mass organic acids in plant root exudates. J. Chromat. A. 1011, 233-240.

Cu S T T, Hutson J and Schuller K A 2005 Mixed culture of wheat (Triticum aestivum L.) with white lupin (Lupinus albus L.) improves the growth and phosphorus of the wheat. Plant Soil 272, 143-151.

Dinkelaker B and Marschner H 1992 In vivo demonstration of acid phosphatase activity in the rhizosphere of soil-grown plants. Plant Soil 144, 199-205.

Dinkelaker B, Römheld V and Marschner H 1989 Citric acid secretion and precipitation of calcium citrate in the rhizosphere of white lupin (Lupinus albus L.). Plant Cell Environ. 12, 285-292.

Dittmer H J 1949 Root hair variations in plant species. Am. J. Bot. 36, 152-155.

Eivazi F and Tabatabai M A 1977 Phosphatases in soils. Soil Biol. Biochem. 9, 167-172.

Fairhust T, Lefroy R, Mutert E and Batjes N 1999 The importance, distribution and causes of phosphorus deficiency as a constraint to crop production in the tropics. Agroforest. Forum 9, 2-8.

Gaume A, Mächler F, De Leon C, Narro L and Frossard E 2001 Low-P tolerance by maize (Zea mays L.) genotypes: significance of root growth and organic acids and acid phosphatase root exudation. Plant Soil 228, 253-264.

Gardner W K, Barber D A and Parberry D G 1983 The acquisition of phosphorus by Lupinus albus L. III. The probable mechanism by which phosphorus movement in the soil/root interface is enhanced. Plant Soil 70, 107-124.

Gerke J, Römer W and Junk A 1994 The secretion of citric acid and malic acid by proteoid roots of Lupinus albus L.: effects on soil solution concentrations of phosphate, iron, and aluminium in the proteoid rhizosphere in samples of an oxisol and luvisol. Z. Pflanzenernähr. Bodenkd. 157, 289-294.

Gilbert G A, Knight J D, Vance C P and Allan D L 1999 Acid phosphatase activity in phosphorus deficient white lupin roots. Plant Cell Eviron. 22, 801-810. 
Gregory P J, 2004 The rhizosphere - a historical perspective from a soil scientist's viewpoint. International Congress Rhizosphere 2004 - Perspective and Challenges, a tribute to Lorenz Hiltner, Munich, Germany. 31 pp.

Hagström J, James W M and Skene K R 2001 A comparison of structure, development and function in cluster roots of Lupinus albus L., under phosphate and iron stress. Plant Soil 232, 81-90.

Imas P, Bar-Yosef B, Kafkafi U and Ganmore-Neumann R 1997 Phosphate induced carboxylate and proton release by tomato roots. Plant Soil 191, 35-39.

Jansa J, Mozafar A and Frossard E 2003 Long-distance transport of $\mathrm{P}$ and $\mathrm{Zn}$ through the hyphae of an arbuscular mycorrhizal fungus in symbiosis with maize. Agronomie 23, 481-488.

Jones D L 1998 Organic acids in the rhizosphere - a critical review. Plant Soil 205, 25-44.

Jones D L and Brassington D S 1998 Sorption of organic acids in acid soils and its implication in the rhizosphere. Eur. J. Soil Sci. 49, 447-455.

Kahm M, Horst W J, Amer F, Mostafa H and Maier P 1999 Mobilization of soil and fertilizer phosphate by over crops. Plant Soil 211, 19-27.

Khaliq A and Sanders F E 2000 Effects of vesicular-arbuscular mycorrhizal inoculation on the yield and phosphorus uptake of field-grown barley. Soil Biol. Biochem. 32, 1691-1696.

Keerthisinghe G, Hocking P J, Ryan P R and Delhaize E 1998 Effect of phosphorus supply on the formation and function of proteoid roots of white lupin (Lupinus albus L.). Plant Cell Environ. 21, 467-478.

Lamont B B 2003 Structure, ecology and physiology of root clusters - a review. Plant Soil 248, 1-19.

Liu J, Uhde-Stone C, Li A, Vance C and Allan D 2001 A phosphate transporter with enhanced expression in proteoid roots of white lupin (Lupinus albus L.). Plant Soil 237, $257-266$

Massonneau A, Langlade N, Leon S, Smutny J, Vogt E, Neumann G and Martinoia E 2001 Metabolic changes associated with cluster root development in white lupin (Lupinus albus L.): relationship between organic acid secretion, sucrose metabolism and energy status. Planta 213, 534-542.

Moritsuka N, Yanai J and Kosaki T 2000 Effect of plant growth on the distribution and forms of soil nutrients in the rhizosphere. Soil Sci. Plant Nutr. 46, 439-447.

Murphy J and Riley J P 1962 A modified single solution method for the determination of phosphate in natural waters. Anal. Chim. Acta 27, 426-430.

Neumann G and Römheld V 1999 Root excretion of carboxylic acids and protons in phosphorus-deficient plants. Plant Soil $211,121-130$

Neumann G, Massonneau A, Martinoia E and Römheld V 1999 Physiological adaptations to phosphorus deficiency during proteoid rootdevelopmentin whitelupin. Planta 208, 373-382.

Neumann G, Massonneau A, Langlade N, Dinkelaker B, Hengeler C, Römheld V and Martinoia E 2000 Physiological aspects of cluster root function and development in phosphorus-deficient white lupin (Lupinus albus L.). Ann. Bot. 85, 909-919.

Neumann G and Martinoia E 2002 Cluster roots - an underground adaptation for survival in extreme environments. Trends Plant Sci. 7, 162-167.

Olsen S R, Cole C V, Watanabe F S and Dean L A 1954 Estimation of available phosphorous in soils by extraction with sodium bicarbonate. U.S.D.A. Circular 939, 1-8.
Penazola E, Corcuera L J and Martinez J 2002 Spatial and temporal variation in citrate and malate exudation and tissue concentration as affected by $\mathrm{P}$ stress in roots of white lupin. Plant Soil 241, 209-221.

Purnell H M 1960 Studies of the family of Proteaceae-I. Anatomy and morphology of the roots of some Victorian species. Aust. J. Bot. 8, 38-50.

Sas L, Rengel Z and Tang C 2001 Excess cation uptake and extrusion of protons and organic acids anions by Lupinus albus under phosphorus deficiency. Plant Sci. 160, 1191-1198.

Sasaki T, Yamamoto Y, Ezaki B, Katsuhara M, Ju Ahn S, Ryan P R, Delhaize E and Matsumoto H 2004 A wheat gene encoding an aluminum-activated malate transporter. Plant J. 37, 645-653.

Schachtman D P, Reid R J and Ayling S M 1998 Phosphorus uptake by plants: from soil to cell. Plant Physiol. 116, 447-453.

Shen J, Rengel Z, Tang C and Zhang F 2003 Role of phosphorus nutrition in development of cluster roots and release of carboxylates in soil-grown Lupinus albus. Plant Soil 248, 199-206.

Tabatabai M A 1994 Soil enzymes. In Methods of Soil Analysis, Part 2. Microbiological and Biochemical Properties. SSSA Book Series No. 5. Eds. R W Weaver, J S Angle and P S Bottomley. pp. 775-833. Soil Sci. Soc. Am, Madison, Wisconsin.

Tabatabai M A and Bremner J M 1969 Use of p-nitrophenyl phosphate for assay of soil phosphatase activity. Soil Biol. Biochem. 1, 301-307.

Vance C P 2001 Symbiotic nitrogen fixation and phosphorus acquisition. Plant nutrition in a world of declining renewable resources. Plant Physiol. 127, 390-397.

Wasaki J, Omura M, Ando M, Shinano T, Osaki M and Tadano T 1999 Secreting portion of acid phosphatase in roots of lupin (Lupinus albus L.) and a key signal for the secretion from the roots. Soil Sci. Plant Nutr. 45, 937-945.

Wasaki J, Yamamura T, Shinano T and Osaki M 2003 Secreted acid phosphatase is expressed in cluster roots of lupin in response to phosphorus deficiency. Plant Soil 248, 129-136.

Watt M and Evans J R 2003 Phosphorus acquisition from soil by white lupin (Lupinus albus L.) and soybean (Glycine max L.), species with contrasting root development. Plant Soil 248, 271-283.

Weisskopf L, Fromin N, Tomasi N, Aragno M and Martinoia E 2005 Secretion activity of white lupin's cluster roots influences bacterial abundance, function and community structure. Plant Soil 268, 181-194.

Wouterlood M, Cawthray G R, Turner S, Lambers H and Veneklaas E J 2004 Rhizosphere carboxylate concentrations of chickpea are affected by genotype and soil type. Plant Soil 261, 1-10.

Yan F, Zhu Y, Müller C, Zörb C and Schubert S 2002 Adaptation of $\mathrm{H}^{+}$-pumping and plasma membrane $\mathrm{H}^{+}$ ATPase activity in proteoid roots of white lupin under phosphate deficiency. Plant Physiol. 129, 50-63.

Zhang W H, Ryan P R and Tyerman S D 2004 Citratepermeable channels in the plasma membrane of cluster roots from white lupin. Plant Physiol. 136, 3771-3783.

Section Editor: C.P. Vance 